\title{
Histological Study of Dysplastic Dermal Tissue in Newborn with Myelomeningocele: A Comparative Analysis of the Population of Myofibroblasts
}

\author{
Elbert Oberto Reyes Graterol Md, Ms, PHd ${ }^{1,2}$; Wilfredo Molina Wills DDs, Msi, Msrh, PHd ${ }^{1 *}$; Wilmer Alfredo Peña Balza Md ${ }^{1}$; Mariana \\ Alejandra Bastidas Guerrero ${ }^{3}$
}

${ }^{1}$ Neurohistology laboratory. Department of Morphological Sciences. Faculty of Medicine. University of Los Andes. Merida-Venezuela.

${ }^{2}$ Neurosurgery Service of the Autonomous Institute University Hospital of Los Andes. Merida-Venezuela.

${ }^{3}$ Student of Medicine.

*Corresponding Author: Wilfredo Molina Wills, Neurohistology laboratory. Department of Morphological Sciences. Faculty of Medicine. University of Los Andes. Merida-Venezuela.

\section{Received Date: 07 December 2021 | Accepted Date: 29 December 2021 | Published Date: 07 January 2022}

Citation: E O R Graterol, Wilfredo M Wills, W A P Balza, M A B Guerrero. (2022). Histological Study of Dysplastic Dermal Tissue in Newborn with Myelomeningocele: A Comparative Analysis of the Population of Myofibroblasts. International Journal of Clinical Case Reports and Reviews. 10(2); DOI: $10.31579 / 2690-4861 / 194$

Copyright: (C) 2022 Wilfredo Molina Wills, This is an open-access article distributed under the terms of the Creative Commons Attribution License, which permits unrestricted use, distribution, and reproduction in any medium, provided the original author and source are credited.

\begin{abstract}
Objectives: Lumbar myelomeningocele is the most common type of spina bifida, a defect of embryonic development, in which an incomplete closure of the vertebral arches is observed in addition to dysplastic alterations of the nervous, meningeal, bone and cutaneous tissue. The tissue response to postoperative closure will depend, among other factors, on the population of pluripotent cells such as myofibroblasts present in the tissue at the edges of the lesion.

The purpose of the following study was to determine the population of myofibroblasts in the dysplasic dermis associated with lumbar myelomeningocele, to compare the population of myofibroblasts of the edges of the lesion with those of the normal skin of the defect, and to assess the usefulness of the Ammoniac Silver Nitrate technique, in the identification of myofibroblasts.

Methods: It was randomly selected 6 newborn patients who went to intervention for the surgical closure of lumbar myelomeningocele, 10 millimeters of both dysplastic and normal eutrophic skin were extracted from each patient, the histological sections were stained with hematoxylin/eosin and ammoniac silver nitrate to detect myofibroblasts.

Immunohistochemistry: Anti-alpha-actin Smooth Muscle Actin (SMA) antibody was used to detect alpha actinpositive intracytoplasmic bodies and subplasmalemal plaques. Results: the presence of myofibroblasts, presence of dense subplasmalemal plaques and positive immunostaining for alpha actin in the area of dysplastic dermal tissue were identified. The amount of myofibroblasts was higher in the dysplasic zone, Ammoniac silver nitrate highlighted the dense subplasmalemal plaques of myofibroblasts. A 5:1 ratio was found when comparing the amount of myofibroblasts of the dysplastic dermis with respect to the healthy one, student's T test showed a standard deviation between samples 1.87 and $\mathrm{p}<0.05$. The differences between the two cell populations studied are statistically significant.
\end{abstract}

Conclusions: The presence of myofibroblasts demonstrates the possibility of generating new post-surgical tissue in the cases studied. Ammoniac silver nitrate is a novel and reliable method in the histological determination of subplaslemal plaques of myofibroblasts.

Keywords: myofibroblasts; connective tissue; dense plates; silver nitrate
Introduction

Fibrosis contributes to a substantial proportion of all natural deaths. Studies provides evidence that perivascular cell, also known as the pericyte, is the cell type responsible for fibrotic disease in skin and 
skeletal muscle [1]. Has been mentioned that the use of off-label tissue graft materials, such as acellular dermal matrix (ADM), for in uterus repair of severe spina bifida (SB), where primary skin layer closure is not possible [2]. The principal role played by the myofibroblast in wound healing and pathological organ remodeling is well established; the general mechanism of extracellular matrix synthesis and of tension production by these cells is well known [3]. Myofibroblast have a role in growth factors secretion, matrix deposition and degradation. Thereby, myofibroblast contributes in both human physiology and pathology [4]. Myofibroblasts are essential for the veracity of the mammalian body by virtue of their role in inflammation and repair, but can also become a threat by their ability to prop up tumor development [5]. Knowing the pluripotent action of myofibroblasts, the question is ihow is the population of myofibroblasts in the dysplastic dermis in patients with myelomeningocele?. The purpose of this study was to determine the population of myofibroblasts in the dysplastic dermis associated with lumbar myelomeningocele, to compare the population of myofibroblasts of the edges of the lesion with those of the normal skin of the defect, and to assess the usefulness of the Ammoniac Silver Nitrate technique, in the identification of myofibroblasts.

\section{Methods}

\section{Selection of cases}

It was randomly selected six newborn patients who went to intervention for surgical closure of lumbar myelomeningocele.

\section{Histological preparation method}

During the surgical procedure, separate samples of 10 square millimeters of both dysplastic and eutrophic (normal) skin were obtained from each patient. The extracted tissue samples were placed in immersion of $10 \%$ buffered formaldehyde (Commercial formaldehyde $40 \%+$ distilled water $+\mathrm{NaH} 2 \mathrm{Po} 4$ (anhydrous) + Na2H2Po4 (anhydrous)). Each sample (dysplasic and normal), was dehydrated, clarified in xylol, and included in paraffin. Serial cuts of 4 micrometers were made obtaining 10 cuts for each sample (dysplastic and healthy) forming for each patient 2 groups of samples A- healthy skin and B- dysplasic skin. The histological sections corresponding to each group of samples were identified, the number selected to be stained with hematoxylin/eosin and impregnated with ammoniac silver nitrate variant. The dyed samples were mounted on object holders and covers with object covers (Martex $\left.{ }^{\circledR}\right)$ fine-tuned with the placement of the object cover. All samples were kept at room temperature and out of reach of light.

\section{Ammoniac silver nitrate technique}

The sheets with the samples were dewaxed with xylol and processed with alcohols of decreasing concentration until ending in distilled water. A 20 $\%$ silver nitrate solution was heated for 15 minutes [solution (A)] and completely immersed in this solution, remaining in it for 15 minutes at 37 ${ }^{\circ} \mathrm{C}$. After this time, the sheets were placed in distilled water for 5 minutes. From a $15.9 \%$ ammonium hydroxide solution [solution (B)], $6 \mathrm{ml}$ was taken and added to solution $\mathrm{A}$, then another $3 \mathrm{~mL}$ (drop by drop) of solution B was added, without the sheets inside. A third solution (solution (C)) was obtained from these mixtures. The sheets remained 15 minutes in solution $\mathrm{C}$ at $37{ }^{\circ} \mathrm{C}$. During the addition of the drops, the progressive turbidity of the solution could be observed. After 15 minutes, the sheets were removed and immersed in a solution of $0.25 \%$ ammonium hydroxide for 3 minutes.

A fourth solution [solution (D)] was prepared. The sheets were removed from the $0,25 \%$ ammonium hydroxide solution after 3 minutes and 15 drops of the D solution were added to solution $\mathrm{C}$, immersed in this solution for 5 minutes and a fifth solution [solution (E)] was prepared in which they were placed for approximately 5 minutes, when extracting them we washed them in 3 changes of distilled water and finally they were dehydrated with alcohols in increasing concentrations in 3 times of 5 minutes each and respective rinsing with xylol in 3 times of 5 minutes each 6 .

\section{Morphometric analysis}

Microphotographs with digital camera model Microscope USB Digital Camera Moticam 2000 were taken, brand Motic ${ }^{\circledR}$, using graduated slide with metric scale. The measurements were made along the major cell axis, taking into account only those cells in which more than $90 \%$ of the soma was visible.

\section{Immunohistochemistry:}

Anti-alpha-actin antibody Smooth Muscle Actin (SMA) Concentrated and Prediluted Mouse Monoclonal Antibody was used. The binding of the primary antibody to its scientific antigenic epitope was performed, and then a secondary antibody was added to bind to the primary antibody and a binding marker to bind the secondary antibody evidenced by a colorimetric reaction.

\section{Cellular quantification}

It was performed in similar optical fields, the same graduated target with the same standard metric scale and the same magnification were used in all histological sections to proceed with cell counting.

\section{Statistical analysis}

The student's T test was used as a statistical test to evaluate the differences or not between the cell populations studied in areas A- of healthy skin and B- of dysplastic skin. The test results were as follows: the null hypothesis for cell populations A and B was equal to zero, the standard deviation between samples 1.87 and $\mathrm{p}<0.05$. The differences between the two cell populations studied are statistically significant.

None of the cases selected for this study had visible evidence of other developmental anomalies or genetic disorders, to perform this study, all procedures in humans were performed in agreement and approval of the histology department of the medical school of the Universidad de los Andes Venezuela and the Department of Neurosurgery of the University Hospital of the Andes, taking into account all the ethical aspects of the Declaration of Helsinki for human research.

\section{Results}

The identification of myofibroblasts was confirmed by the techniques hematoxylin and eosin, immunohistochemistry, ammoniacal silver nitrate and, combination of ammoniac silver nitrate contrasted with $\mathrm{H} / \mathrm{E}$. The characterization was supported by the morphology and dimensions of the cell body7, as well as the morphological characteristics of the nucleus, its relationship with collagen fibers, the presence of dense subplasmalemal plaques and the positive immunostaining for alpha actin.

By examining the reticular dermis of the skin associated with the lumbar myelomeningocele of newborns under the optical microscope, the distribution of cellular and fibrillar connective elements was observed. The myofibroblasts are oriented in the cases studied relatively in the same direction of the cutting plane (Fig. 1) and, between them; they are organized in parallel by all the observed extension (Fig. 2). With regard to morphology, ten myofibroblasts were selected as a reference that met the aforementioned criteria and were demonstrated as tapered cells with an average size between 60-70 $\mu \mathrm{m}$ (Fig. 1, 2), in which it was possible to observe with ammoniac silver nitrate technique some argirophilic subplasmalemal plaques, and oval nuclei, central, with fine lumps of marginal heterochromatin.

The alpha actin immunolabeling technique allowed the detection of alpha actin-positive intracytoplasmic bodies and intensely stained subplasmalemal plasma cells (Fig. 3). When using the variant of the 
ammoniac silver nitrate technique in the preparations, the impregnation of well-defined subplasmalemal argirophilic plaques was observed in the myofibroblasts (Fig. 2 and 4).

For each patient under study, the amount of myofibroblasts present in the reticular dermis of healthy skin surrounding the defect was compared with those present in the dysplastic area of the lumbar myelomeningocele. The phenomenon of cell increase presented by the dysplastic area with respect to the healthy area was observed. (fig. 5 and 6). Fibrocytes and fibroblasts of varying lengths, ranging in size from 50 to 100 micrometers, were observed.

The approximate area of $192 \mu \mathrm{m}$ squares of the clear field was studied and a count of the number of myofibroblasts in the dermis was performed, finding an average value of 11.8 cells in dysplastic skin for every 2.3 cells in normal skin (Table 1), obtaining a ratio of 5.3:1 respectively.

Table 1. Quantification of myofibroblasts in dysplastic skin of lumbar myelomeningocele and normal skin.

\begin{tabular}{|l|l|l|}
\hline $\begin{array}{l}\text { Newborn } \\
\text { patients }\end{array}$ & $\begin{array}{l}\text { Number of myofibroblasts per } \\
\text { brightfield area }(\mathbf{1 9 2} \boldsymbol{\mu m})\end{array}$ \\
\hline & $\begin{array}{l}\text { Reticular dermis } \\
\text { normal skin }\end{array}$ & $\begin{array}{l}\text { Reticular dermis } \\
\text { dysplasic skin }\end{array}$ \\
\hline 1 & 3 & 10 \\
\hline 2 & 2 & 12 \\
\hline 3 & 2 & 11 \\
\hline 4 & 1 & 12 \\
\hline 5 & 2 & 14 \\
\hline 6 & 4 & 12 \\
\hline Average & $\mathbf{2 , 3}$ & $\mathbf{1 1 , 8}$ \\
\hline
\end{tabular}

Table 1: shows the largest amount of myofibroblasts present in the reticular dermis of dysplasic skin compared to normal skin at the edges of the lesion.

\section{Optical microphotographs (Figures)}

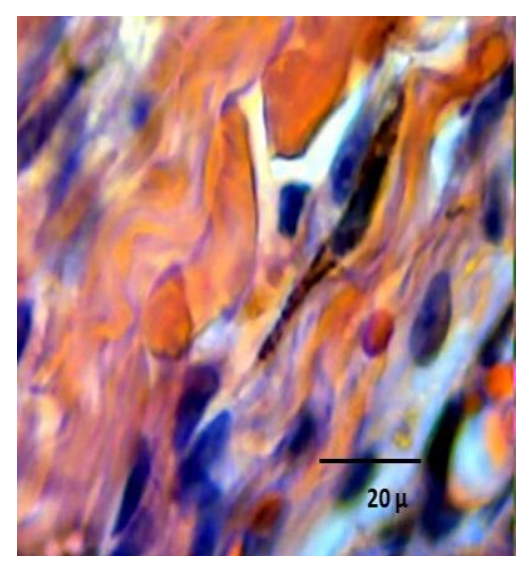

Figure 1. Hematoxylin-eosin. 100X. Reticular dermis of the normal skin surrounding the defect: lumbar myelomeningocele. A tapered cell stands out, with a single oval nucleus with brown cytoplasmic grains. It differs from the typical basophilic cytoplasm fibroblast with bulky and euchromatic nucleus. It is possible to discriminate from large bundles of eosinophilic collagen fibers.

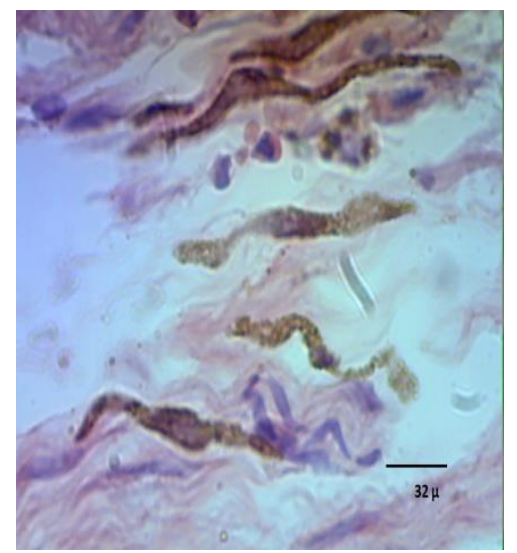

Figure 2: Ammoniac silver nitrate contrasted with H/E. Reticular dermis of the dysplastic skin of the lumbar myelomeningocele. The abundant presence of myofibroblasts arranged in parallel stands out, with their typical subplasmalemal argirophilic plaques. 


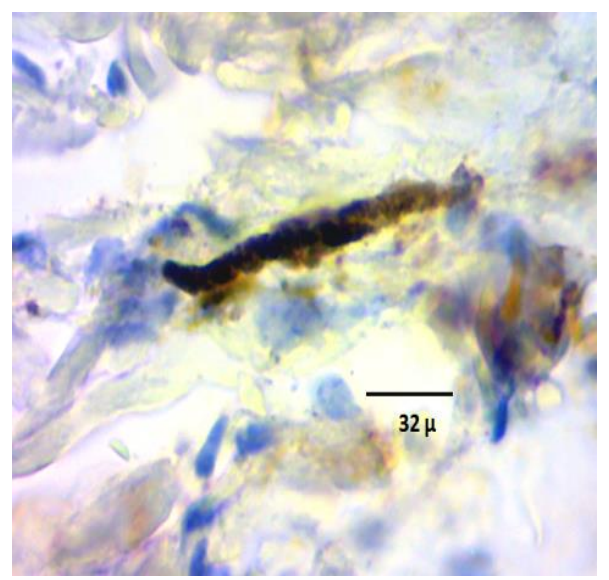

Figure 3: Immunohistochemistry. 100X. Reticular dermis of the normal skin surrounding the defect: lumbar myelomeningocele. The presence of dermal myofibroblasts is observed, in which cytoplasmic grains with positive immunomarking and dense subplasmalemal plaques stand out.

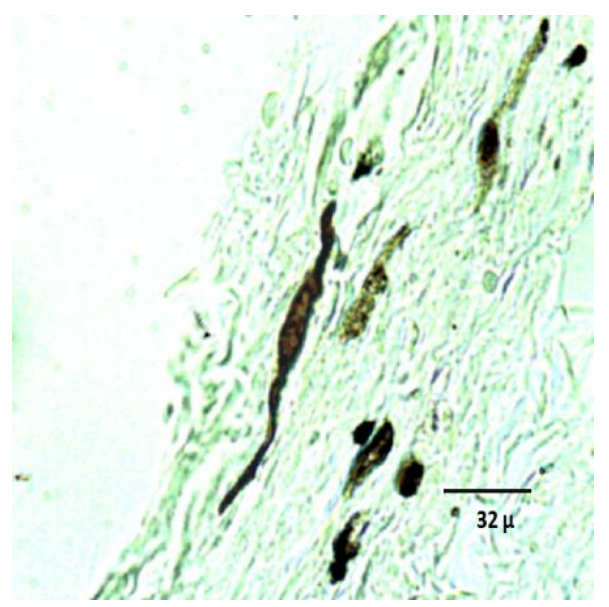

Figure 4: Ammoniac silver nitrate. 100X. Reticular dermis of healthy skin surrounding the defect: lumbar myelomeningocele. Typical myofibroblasts in which the evident impregnation of macrophilic structure of subplasmalemal localization is appreciated.

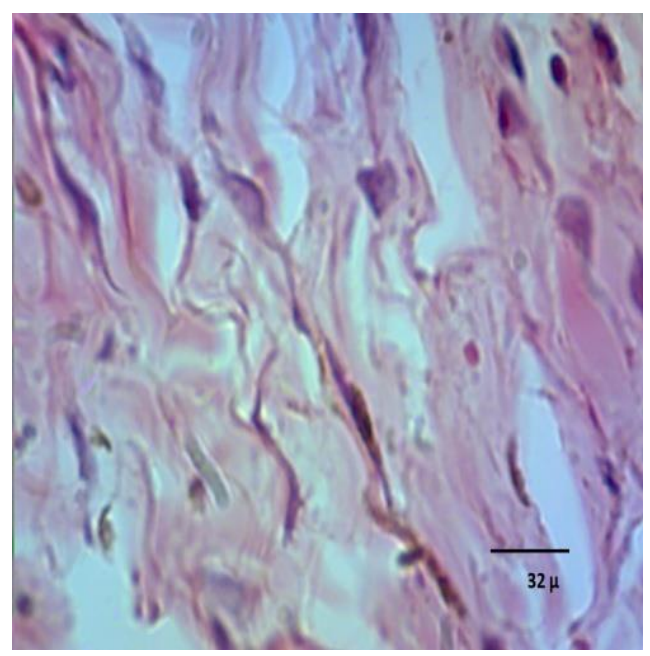

Figure 5: Ammoniac silver nitrate contrasted with H/E. 40X. Reticular dermis of healthy skin surrounding the defect in lumbar myelomeningocele. In the present sample highlights the small amount of myofibroblasts with their typical dense subplasmalemal plaques. 


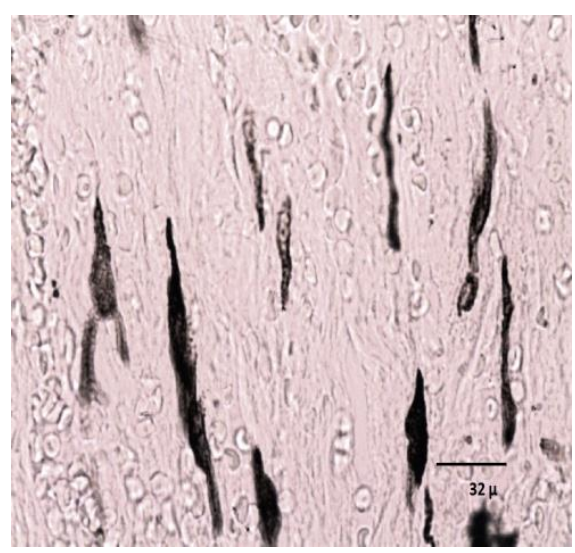

Figure 6: Ammoniac silver nitrate contrasted with H/E. 100X. Reticular dermis of the dysplasic skin of the lumbar myelomeningocele. The process of cell augmentation experienced by myofibroblasts is appreciated with respect to the dermis observed in Figure 5; as well as its tapered morphology, its parallel arrangement and its perfect discrimination of other cellular and fibrillar elements of the connective tissue.

\section{Discussion}

The findings obtained in this study suggest morphological evidence of tissue changes associated with the processes of dysplastic skin development in newborn patients with lumbar myelomeningocele that generate debates of neurosurgical interest inherent in decision-making on the management of the various types of presentation of this pathology. Taking into account the process of dermoepidermal repair both in cases addressed in a deferred manner and, in those that are intervened of early manner according to intervention protocols in Neurosurgery.

Myofibroblasts play a crucial role in the proliferative-contractile phase of wound healing and repair processes, providing approximately $30 \%$ of the definitive tensile strength of the repaired tissue8. These observations allow understanding the defects that initially everted edges have and that culminate in the flat edges after contractile process. It is from these edges that re-epithelializations begin, which can be total or partial.

Connective tissue is rich in fixed and mobile cells, fibers and fundamental substance, for which effective and reproducible histological methods must be, used which allows discriminating cells such as myofibroblasts from other elements such as fibroblasts, fibrocytes and large bundles of collagen fibers. Ammoniac silver nitrate is attractive to fulfill this purpose since it is able to place in evidence tapered cells with sizes between 6070 micrometers, with dense argyrophil subplasmalemal plaques, elements, that are absent in fibrocytes and fibroblasts, that regularly have sizes ranging between 50 and 100 micrometers.

\section{Conclusiones}

Through the present study, it was observed that the variant of ammoniac silver nitrate is applicable, reproducible and adaptable to the area of histopathology, being a sensitive method for the characterization of myofibroblasts since it allows highlighting the dense subplasmalemal plaques and the cellular limits in a clear tissue background. A higher population density of myofibroblasts was observed in the dysplastic dermis in contrast to the normal dermis suggesting a natural restorative effort towards the lining of the defect.

\section{Conflict of Interest}

The authors declare that there is no conflict of interests regarding the publication of this paper.

\section{Acknowledgment.}

To the University of Los Andes, to the Department of Morphological Sciences, to the Academic Unit of Histology, and to Professor Arisela Díaz Cedeño, who dedicated her life to teaching and research, for welcoming us to the world of neurohistology.

\section{References}

1. Duffield J. (2012). The elusive source of myofibroblasts: problem solved?. Nature Medicine. 18:1178-1180.

2. Lovepreet K. Mann, Jong Hak Won, Rajan Patel, Eric P. Bergh, Jeannine Garnett Meenakshi B. Bhattacharjee, Ponnada A. Narayana, Ranu Jain, Stephen A. Fletcher, Dejian Lai, Ramesha Papanna. (2021) Allografts for Skin Closure during In Utero Spina Bifida Repair in a Sheep Model. Journal of clinical medicine. 10(21).

3. Hinz B, Phan S, Thannickal V, et al. (2007). The Myofibroblast: One Function, Multiple Origins. The American Journal of Pathology. 170(6):1807-1816.

4. Bhavana S Bagalad, K P Mohan Kumar and H K Puneeth. (2017). Myofibroblasts: Master of disguise. J Oral Maxillofac Pathol. 21(3):462-463.

5. Shirol PD, Shirol DD. (2012). Myofibroblasts in health and disease. Int J Oral Maxillofac Pathol. 3:23-27.

6. Reyes Elbert et al. (2017). Variante de la tinción de nitrato de plata amoniacal para destacar placas densas (fibronexus) del Miofibroblasto. Scientifica. 15(1): 11-16.

7. Ramos, Carlos et al. (2004). El Miofibroblasto, una célula multifuncional en la patología pulmonar.

8. Valencia Basto, Carlos. (2010). Cicatrización: proceso de reparación tisular. Aproximaciones terapéuticas. Investigaciones Andinas. 20(12):100. 